FETAL AND NEONATAL EDITION

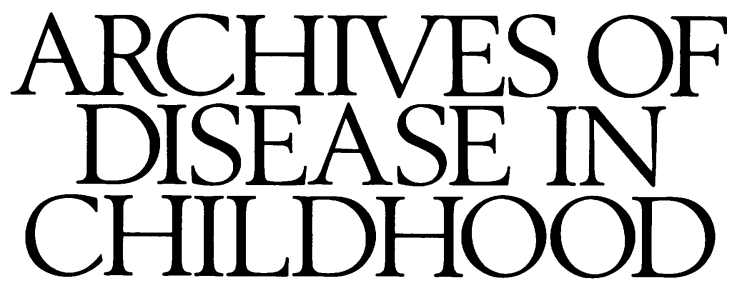

The Fournal of the British Paediatric Association

\title{
Annotations
}

\section{Herpes simplex virus infection in pregnancy}

The incidence of neonatal herpes simplex virus (HSV) infection is about $200-500$ per 100000 live births in the USA $^{12}$ but has been estimated at two per 100000 in the UK. ${ }^{3}$ Neonatal HSV results from perinatal acquisition from the maternal genital tract in about $85 \%$ of cases. Approximately $5 \%$ of cases result from transplacental spread resulting in intrauterine $\mathrm{HSV},{ }^{4}$ while about $10 \%$ of cases are secondary to postnatal acquisition. ${ }^{5}$

\section{Intrauterine $\mathrm{HSV}$ infection}

Nine $(4 \cdot 7 \%)$ of 192 infants with neonatal HSV infection enrolled in a large prospective US study had evidence of intrauterine HSV infection. ${ }^{4}$ These nine babies, and four other babies selectively referred to the authors, had a combination of skin lesions and scars at birth, chorioretinitis, microcephaly or hydranencephaly, and microphthalmia. Eight mothers were asymptomatic, four had apparent primary genital HSV infection (two in the first and two in the third trimester), and one mother had recurrent genital herpes. The risk of intrauterine infection if the mother has proved primary genital herpes in pregnancy is unknown, but is probably very small. ${ }^{6}$

\section{Maternal HSV infection}

About $70 \%$ of babies with neonatal HSV infection are born to mothers with no history of genital lesions. ${ }^{5}$ Most neonatal cases result from primary maternal HSV infection around the time of delivery, as determined by $\operatorname{IgM}$ production, although the maternal infection may be asymptomatic. ${ }^{1}$ Of those asymptomatic women who have HSV detected in early labour, about a third have primary genital infection, and their babies are 10 times more likely to develop neonatal HSV than babies of women with asymptomatic reactivation. A distinction has been drawn between women with primary genital herpes, who become infected with either HSV-1 or HSV-2 in the absence of prior HSV antibodies, and those with so called non-primary infection, who have a first symptomatic genital infection, usually with HSV-2, in the presence of neutralising HSV IgG antibodies, usually to HSV-1. For the USA it has been estimated that the relative proportions of recurrent, primary, and non-primary HSV infections at the time of labour are $91 \cdot 3 \%, 2 \cdot 1 \%$, and $6 \cdot 6 \%$ respectively. ${ }^{7}$ It was originally thought that non-primary maternal infections were less likely to lead to neonatal infection. ${ }^{6}$ However, in a recent study of babies born vaginally to asymptomatic women who were found by viral culture to be shedding HSV at delivery, infection developed in two of five babies of mothers with primary infection and four of 13 with non-primary infection, ${ }^{1}$ suggesting that antiHSV-1 antibody may not be as protective against HSV-2 infection as once thought.

Specific maternal IgG antibody against the relevant HSV serotype protects against neonatal infection, but this protection is not absolute. Prober $e t a l^{8}$ and Brown et al ${ }^{1}$ studied babies born vaginally to women with recurrent HSV infection who were shedding virus at the time of delivery. In the study of Prober et al none of 34 exposed babies became infected, and their neutralising antibody levels to HSV type 2 were significantly higher than those of historically infected babies. In the study of Brown et al, one of 33 exposed babies became infected. Thus neonatal HSV infection may follow recurrent maternal HSV infection, although it is more common following primary (and non-primary) infection.

\section{Neonatal infection}

Neonatal HSV infection may be localised to skin, eye or mouth, may be generalised to involve the liver, adrenals, lungs, and other organs including the brain, may cause isolated pneumonitis, or there may be isolated meningoencephalitis. The prognosis of all but the first form is poor. Without antiviral treatment about $70 \%$ of babies with localised HSV infection will progress to disseminated infection. ${ }^{9}$ With increasing recent recognition that neonatal vesicular skin eruptions are often herpetic, specific diagnosis by immunofluorescent staining or electron microscopy and early antiviral treatment, there has been a marked fall in the proportion of cases of neonatal HSV infection in the USA that are disseminated, and a concomitant increase in the proportion of babies with localised disease. ${ }^{10}$

The two drugs that have been shown to be effective in neonatal HSV infection are acyclovir and adenosine arabinoside (ara- $\mathrm{A}$ ), and the two drugs are almost identical in terms of mortality and long term morbidity. ${ }^{11}$ Even with these drugs, however, the mortality of disseminated disease is $50-60 \%{ }^{11}$

There is considerable concern that neonatal HSV infection may cause chronic, insidious central nervous system infection leading to progressive neurodevelopmental deterioration. Gutman et al described babies with neonatal HSV encephalitis who deteriorated after completing antiviral treatment or had progressive deterioration over their first year of life. ${ }^{12}$ Even more alarmingly, Whitley et al found that four of 71 babies with neonatal HSV infection localised to the skin, eyes, or mouth had long term neurological damage. ${ }^{13}$ All four babies had HSV-2 and had three or more recurrences of 
Management of $H S V$ infection in pregnancy

\begin{tabular}{|c|c|c|c|}
\hline Maternal infection & Risk to fetus/baby & Management of mother & Management of baby \\
\hline Primary in 1st trimester & $\begin{array}{l}\leq 20 \% \text { of abortion or } \\
\text { intrauterine infection }\end{array}$ & No action & As for recurrent herpes \\
\hline $\begin{array}{l}\text { First ever lesions at delivery } \\
\text { (a) Primary }\end{array}$ & $\begin{array}{l}\text { About } 50 \% \text { risk of } \\
\text { neonatal } \mathrm{HSV}^{6}\end{array}$ & Caesarean section & $\begin{array}{l}{ }^{*} \text { Cultures if caesarean } \\
\text { section performed: } \\
\text { treat with acyclovir } \\
\text { if positive. } \\
\text { Prophylactic acyclovir } \\
\text { if delivers vaginally }\end{array}$ \\
\hline (b) Recurrence & Unknown & Vaginal delivery & $\begin{array}{l}\text { Cultures: treat } \\
\text { with acyclovir if } \\
\text { positive }\end{array}$ \\
\hline & $\begin{array}{l}\text { About } 30 \% \text { chance } \\
\text { infection is primary }\end{array}$ & Caesarean section & $\begin{array}{l}\text { *Cultures: treat with } \\
\text { acyclovir if positive }\end{array}$ \\
\hline $\begin{array}{l}\text { Recurrent genital herpes, } \\
\text { no signs or symptoms }\end{array}$ & 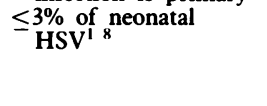 & Vaginal delivery & $\begin{array}{l}\text { Observe for signs or } \\
\text { "cultures and treat } \\
\text { with acyclovir if } \\
\text { positive }\end{array}$ \\
\hline
\end{tabular}

${ }^{*}$ Cultures $=$ nasopharyngeal + conjunctival viral cultures at $24-48$ hours of age.

skin vesicles in the first year of life. Strong consideration should be given to long term oral acyclovir prophylaxis, perhaps for a year, for all babies with neonatal HSV encephalitis and for babies with localised HSV-2 infection who have three or more skin recurrences.

\section{Prevention of neonatal HSV infection}

The risk to the fetus of stillbirth or intrauterine infection when the mother has primary genital herpes in the first trimester is unknown, but probably small. ${ }^{6}$ Acyclovir treatment of the mother under these circumstances has not been evaluated. Acyclovir appears to cross the placenta only in small quantities, ${ }^{14}$ and its safety for the fetus is unproved, so its use does not seem indicated.

The transmission rate to babies at highest risk, those whose mothers have active, primary genital herpes at delivery, is about $50 \%$ if they are delivered vaginally. ${ }^{6}$ Caesarean section, particularly if performed within 24 hours of membrane rupture, reduces the risk of neonatal HSV infection, ${ }^{15}$ although some babies, perhaps $15-20 \%$, will still be infected.

In clinical practice, it is not always clear whether a woman presenting with her first episode of clinical genital herpes infection at delivery has primary or recurrent disease. About $30 \%$ of such women will have primary infection. ${ }^{1}$ If there is not sufficient time to determine whether the mother has specific IgM, then it seems wise to advise caesarean section.

The risk to a baby of an asymptomatic woman with a history of recurrent genital herpes is low. ${ }^{18}$ The baby should be delivered vaginally. When a mother with recurrent genital herpes has active genital lesions at term, either symptomatic or on cervical examination, the risk to the baby is probably higher than if she is asymptomatic since the baby is likely to receive a greater viral load. Some authorities would advise caesarean section, although we feel that a more conservative approach is acceptable (see table). At present there are insufficient data on safety to advise giving acyclovir to pregnant women with HSV infection.

At one stage it was widely advocated that women with a history of recurrent genital herpes should have screening cervical viral cultures taken near term, but this would prevent very few cases of neonatal herpes. In the USA it would cost $\$ 1.9$ million per case averted and there would be one maternal death from complications of caesarean section for every 10 neonatal cases prevented. ${ }^{16}$ Rapid antigen detection for HSV in genital specimens at delivery would identify most at-risk babies, but result in a large number of caesarean sections. Libman et al have analysed different strategies for prevention of neonatal HSV infection, and concluded that maternal physical examination at onset of labour would give the best results in terms of numbers of cases of neonatal HSV averted for least number of extra caesarean sections. ${ }^{7}$
There is no clear consensus as to the management of asymptomatic babies born to women with genital herpes under the different circumstances described above. The alternatives are that the baby should be treated with acyclovir from birth, should have nasopharyngeal and conjunctival viral cultures taken at $24-48$ hours of age (indicating true colonisation rather than surface colonisation), and be treated with acyclovir only if positive, or should simply be observed and treated if symptomatic. ${ }^{17}$ Evidently the greater the risk of neonatal HSV developing, the more reasonable it is to use aggressive intervention. Possible strategies are outlined in the table. Any at-risk baby with signs suggestive of neonatal HSV infection should be treated with acyclovir or ara-A until the baby's infection status is clarified.

\section{DAVID MCINTOSH} DAVID ISAACS

Department of Immunology and Infectious Diseases,

Royal Alexandra Hospital for Children,

Camperdown, NSW 2050,

Australia

1 Brown AZ, Benedetti J, Ashley $\mathrm{R}$, et al. Neonatal herpes simplex virus infection in relation to asymptomatic maternal infection at the time of labour. $N$ Engl $\mathcal{f}$ Med 1991;324:1247-52.

2 Whitley RJ. Herpes simplex virus infections. In: Remington JS, Klein JO, eds. Infectious diseases of the fetus and newborn infant. 3rd Ed. Philadelphia: WB Saunders, 1990:282-305.

3 Hall S, Glickman B. The British paediatric surveillance unit. Arch Dis Child 1988;63:344-6.

4 Hutto C, Arvin A, Jacobs R, et al. Intrauterine herpes simplex virus infections. f Pediatr 1987;110:97-101.

5 Yeager AS, Arvin AM. Reasons for the absence of a history of recurrent genital infections in mothers of neonates infected with herpes simplex virus. Pediatrics 1984;73:188-93.

6 Brown ZA, Vontver LA, Benedetti J, et al. Effects on infants of a first episode of genital herpes during pregnancy. $N$ Englf Med 1987;317:1246-51.

7 Libman SD, Dascal A, Kramer MS, Mendelson J. Strategies for the prevention of neonatal infection with herpes simplex virus: a decision analysis. Rev Infect Dis 1991;13:1093-104.

8 Prober CG, Sullender WM, Yasukawa LL, Au DS, Yeager AS, Arvin AM. Low risk of herpes simplex virus infections in neonates exposed to the virus at the time of vaginal delivery to mothers with recurrent genital herpes at the time of vaginal delivery to mothers with recurrer
simplex virus infections. $N$ Engl 7 Med $1987 ; 316: 214-4$.

9 Whitley RJ, Nahmias AJ, Visintine AM, et al. The natural history of herpes simplex virus infection of mother and newborn. Pediatrics 1980;66:489-94.

10 Whitley RJ, Corey L, Arvin A, et al. Changing presentation of herpes simplex Whitley RJ, Corey L, Arvin A, et al. Changing presentation
virus infection in neonates. F Infect Dis 1988;158:109-16.

11 Whitley R, Arvin A, Prober C, et al. A controlled trial comparing vidarabine with acyclovir in neonatal herpes simplex viral infection. $N$ Engl $\mathcal{F}$ Med 1991;324:444-9.

12 Gutman LT, Wilfert CM, Eppes S. Herpes simplex virus encephalitis in children: analysis of cerebrospinal fluid and progressive neurodevelopmental deterioration. F Infect Dis 1986;154:415-21.

13 Whitley R, Arvin A, Prober C, et al. Predictors of mortality and morbidity in neonates with herpes simplex virus infections. N Engl f Med 1991;324: $450-4$.

14 Greffe BS, Dooley SL, Deddish RB, Krasny HC. Transplacental passage of acyclovir. F Pediatr 1986;108:1020-1.

15 Nahmias AJ, Keyserling HH, Kerrick G. Herpes simplex. In: Remington JS, Klein JO, eds. Infectious diseases of the fetus and newborn infant. 2nd Ed. Philadelphia: WB Saunders, 1983:156-90.

16 Binkin NJ, Koplan JP, Cates W, et al. Preventing neonatal herpes: the value of weekly viral cultures in pregnant women with recurrent genital herpes. FAMA 1984;251:2816-21.

17 Overall JC, Whitley RJ, Yeager AS, McCracken GM, Nelson JD. Prophylactic or anticipatory antiviral therapy for newborns exposed to herpes simplex infection. Pediatr Infect Dis 1984;3:193-5. 